\title{
FURTHER STUDIES ON ISOLATION IN THE BUTTERFLY MANIOLA JURTINA L.
}

\author{
W. H. DOWDESWELL \\ Biology Department, Winchester College \\ E. B. FORD \\ Genetic Laboratories, Zoology Department, Oxford \\ K. G. McWHIRTER \\ Genetic Laboratories, Zoology Department, Oxford
}

Received 21.iii.56

Our previous studies (W. H. D. and E. B. F., I 949-55) of the butterfly Maniola jurtina in the Isles of Scilly and elsewhere have established that the distribution of spots on the under-side of the hind-wings provides an effective method of quantifying variation in both sexes, and that it can be used as a means of detecting evolutionary divergence in different colonies. It would appear unlikely that the presence or absence of spots could, in itself, be of any selective value, and we must conclude that variations in spotting are associated with other characteristics, probably of a physiological kind.

One of the features of our work on $M$. jurtina in Scilly has been the discovery that, while the spot-distribution in the males is everywhere very similar, that of the females varies from one isolated colony to another but is stabilised at a constant value in each. One of our objects in August 1954 and I955 was to study the effects of various types of ecological barriers in bringing about this isolation. This necessitated :

(a) confirmation of some of our findings in former years.

(b) an examination of certain localities which we had not previously visited.

\section{SMALL ISLANDS \\ (a) Tean (see Map I)}

The conditions on the island in I954 were much the same as they had been the year before. The growth of grass in area 2 (due to lack of grazing) and the inroads of bracken at its southern end had resulted in its union with area $I$ as a single continuous locality. The grass in area 4 which, like area 2 , had previously been short and lawn-like, was now long and had ceased to form a barrier to the movement of $M$. jurtina. Thus the island now contained two colonised localities, one at the southern extremity (areas I and 2), the other on the western promontory (arcas 4 and 5 ). These were separated by area 3 which, until I95 I, had supported a large population of M. jurtina. But the removal, in the late summer of $195^{\circ}$, of a herd of cattle had resulted in a heavy growth of the vegetation previously 
controlled by grazing and trampling. By 1954, therefore, an impenetrable mass of bramble and bracken covered the whole of area 3 . $M$. jurtina was now absent there, and the region thus constituted an effective barrier between the southern and western communities. On visiting the island in 1955 this situation was found to persist.

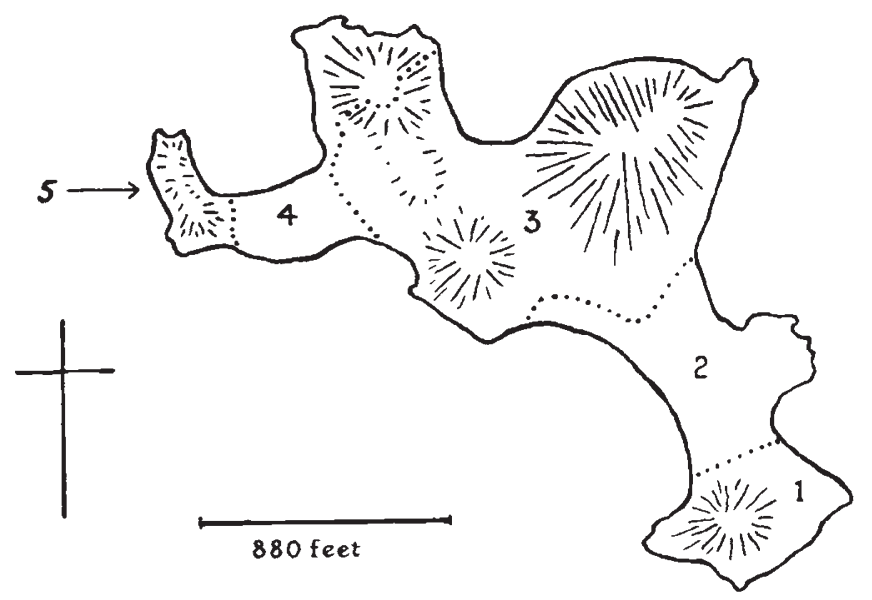

Map. I. Tean (Isles of Scilly). Boundaries of collecting areas.

(i) Males. Our sampling in 1953 showed that the population of area I had maintained a stable spot-distribution since 1946 , with a single large mode at two spots (4). The I954 sample conformed closely with that of the previous year (table I). The male spotdistribution in this colony had thus remained unchanged for a period

TABLE I

Spot-distribution in male Maniola jurtina on Tean (area 1 ) in 1953 and 1954

\begin{tabular}{|c|c|c|c|c|c|c|c|c|c|}
\hline & Spots : & o & I & 2 & 3 & 4 & 5 & Total & Difference \\
\hline I 953 & . & 2 & 8 & 73 & 21 & 9 & I & ${ }_{114}$ & \multirow{2}{*}{ N.S. } \\
\hline 1954 & . & 2 & I 6 & 90 & 26 & 9 & 2 & 145 & \\
\hline
\end{tabular}

In this and all subsequent tables, N.S. denotes "Not significant" and S. denotes

"Significant". Figures for $\chi^{2}$ are included where there is any question of doubt.

of nine years. It is typical of the Scillies in general, and also of southern England.

(ii) Females. Samples from areas I and 5 in 1954 are compared with those of the previous year in table 2. In area I spotting of the females, like that of the males, had remained unchanged, showing the bimodal distribution characteristic of the previous eight years with the smaller mode at no spots and the larger at two. 
Our studies in I 953 had shown the colony in area I to be similar in spot-distribution to the small population in area 5. It was, therefore, of much interest to discover that in 1954 a significant change had taken place in the area 5 colony since the previous year (see table 2), and that its spot-distribution now differed once more from that in area I (see tables 3 and 4 ).

A significant difference between the two colonies had, in fact, become evident in $195 \mathrm{I}$ when area 4 was still heavily grazed and constituted an ecological barrier, isolating area 5 from the rest of the island (3). It was, however, relatively slight, though the larger mode was then at o spots. This distinction had disappeared in 1953 when the area 5 and area I colonies were once more substantially the same (4), as in $195^{\circ}$.

TABLE 2

Spot-distribution in female Maniola jurtina from two colonies on Tean in 1953 and 1954

\begin{tabular}{|c|c|c|c|c|c|c|c|c|}
\hline Spots : & 0 & I & 2 & 3 & 4 & 5 & Total & Difference \\
\hline $\begin{array}{l}\text { Area I (r } 953) \\
\text { Area I (1954) }\end{array}$ & $\begin{array}{l}32 \\
30\end{array}$ & $\begin{array}{l}\text { I I } \\
\text { I } 4\end{array}$ & $\begin{array}{l}46 \\
49\end{array}$ & $\begin{array}{l}2 \text { I } \\
\text { II }\end{array}$ & $\begin{array}{l}3 \\
1\end{array}$ & $\begin{array}{l}\text { I } \\
\text { I }\end{array}$ & $\begin{array}{l}114 \\
106\end{array}$ & N.S. \\
\hline $\begin{array}{l}\text { Area } 5 \text { (1953) } \\
\text { Area } 5 \text { (1954) }\end{array}$ & $\begin{array}{l}30 \\
13\end{array}$ & $\begin{array}{r}14 \\
18\end{array}$ & $\begin{array}{l}54 \\
68\end{array}$ & $\begin{array}{l}\text { I } 3 \\
\text { I }\end{array}$ & $\begin{array}{l}3 \\
5\end{array}$ & $\begin{array}{l}0 \\
0\end{array}$ & $\begin{array}{l}114 \\
115\end{array}$ & $\left\{\begin{array}{l}\left(\chi_{(3)}^{2}=8.8\right. \\
P<0.05\end{array}\right.$ \\
\hline
\end{tabular}

We are thus faced with an interesting situation. Two populations have each expanded into a new area which was formerly a barrier to them. That in area I has extended across area 2, while that in area 5 has colonised area 4 . The two colonies are now held apart by area 3 which has become a barrier. In so expanding, the population of area I (now that of areas I and 2) has remained unaltered, while the area 5 community (now that of areas 4 and 5) has undergone a change of spotting. Why has an extension of range had no effect in one locality but a marked effect in the other? A possible explanation is as follows. The population of area $\mathrm{I}$ has spread across area 2 without adjusting its spot-frequency because the ecology of the two places has become very similar. Not only has the grass ceased to be lawn-like, but bracken has encroached across most of area 2 thus affording much the same degree of shelter that has always been available to $M$. jurtina in area $\mathrm{I}$.

On the contrary, the population in area 5 has spread eastwards because area 4 has become habitable to it, although it is not at all like area 5. Colonisation has only been possible because of the growth of long grass. The sheltering bracken so characteristic of areas I, 2 and 5 is absent from area 4 , and the ecological conditions there are thus unlike those occurring anywhere else on the island. 
It may, thus, be something more than a coincidence that in area 2, where a mixture of long grass and bracken prevails, the Tean population has retained its familiar characteristics; while, on the other hand, in area 4, which is quite different from any which has

TABLE 3

Spot-distribution in female Maniola jurtina from different areas on Tean in 1954

\begin{tabular}{|c|c|c|c|c|}
\hline $\begin{array}{c}\text { Spot } \\
\text { numbers }\end{array}$ & Area I & $\begin{array}{c}\text { Area 2 } \\
\text { (north edge) }\end{array}$ & Area 4 & Area 5 \\
\hline $\begin{array}{l}0 \\
1 \\
2 \\
3 \\
4 \\
5\end{array}$ & $\begin{array}{r}30 \\
\text { I4 } \\
49 \\
\text { I I } \\
\text { I } \\
\text { I }\end{array}$ & $\begin{array}{r}31 \\
19 \\
55 \\
3 \\
0 \\
0\end{array}$ & $\begin{array}{r}13 \\
17 \\
62 \\
8 \\
6 \\
3\end{array}$ & $\begin{array}{r}13 \\
18 \\
68 \\
11 \\
5 \\
0\end{array}$ \\
\hline Totals . & 106 & 108 & 109 & 115 \\
\hline
\end{tabular}

previously supported jurtina on the island, the spotting has undergone a striking modification. This, of course, also affects the population in area 5 which is in no way isolated from that in area 4 . Thus the single population now occupying both these areas has had to adjust

TABLE 4

Comparison of spotting in female Maniola jurtina

from different areas on Tean in 1954

\begin{tabular}{|c|c|c|c|c|}
\cline { 2 - 5 } \multicolumn{1}{c|}{ Areas } & $\mathbf{I}$ & $2^{*}$ & 4 & 5 \\
\hline $\mathbf{I}$ & $\ldots$ & N.S. & $\begin{array}{c}\text { just } \\
>0 \cdot 02\end{array}$ & $<0.02$ \\
\hline $2^{*}$ & $\ldots$ & $\ldots$ & $<0.001$ & $<0.001$ \\
\hline 4 & $\ldots$ & $\ldots$ & $\ldots$ & N.S. \\
\hline 5 & $\ldots$ & $\ldots$ & $\ldots$ & $\ldots$ \\
\hline
\end{tabular}

Figures are values of $\mathrm{P}$ derived from $2 \times n$ tables. Comparisons are made by reading the figures or letters at the point where horizontal and vertical columns intersect.

itself to the average of the dissimilar ecological conditions which they provide, resulting in a different spot-distribution from any previously recorded on Tean.

Owing to other commitments it was only possible in I 955 to obtain a small sample of females from area I (table 5). The distribution of spotting is at least strongly suggestive that no change had taken place since the previous year. 
(b) Great Ganilly (males and females)

In i955, much of our work was centred on the eastern islands of Scilly (see map 2). It was thus possible to devote a day to collecting on Great Ganilly so as to obtain a sample of jurtina for comparison with those of I95 I and $1953(3,4)$.

\section{TABLE 5}

Spot-distribution in female Maniola jurtina from Tean

area $I$ in 1955

\begin{tabular}{|c|c|}
\hline Spot numbers & Total \\
\hline \multirow{2}{*}{$\mathrm{I}$} & 6 \\
2 & 3 \\
3 & $\mathrm{I} 2$ \\
4 & 3 \\
5 & 2 \\
& $\cdots$ \\
\hline
\end{tabular}

TABLE 6

Spot-distribution in male Maniola jurtina from Great Ganilly in 1951 and 1955

\begin{tabular}{|cc|c|c|c|c|c|c|c|}
\hline \multicolumn{2}{|c|}{ Spots : } & 0 & $\mathrm{I}$ & 2 & 3 & 4 & 5 & Total \\
\hline $\mathrm{I} 95^{\mathrm{I}} \cdot$ & $\cdot$ & 0 & 2 & 33 & 27 & $\mathrm{I} 3$ & $\mathrm{I}$ & 76 \\
$\mathrm{I} 955$ & $\cdot$ & 0 & $\mathrm{I}$ & 20 & 10 & $\mathrm{I}$ & 2 & 34 \\
\hline
\end{tabular}

TABLE 7

Spot-distribution in female Maniola jurtina from

Great Ganilly in 195I, 1953 and 1955

\begin{tabular}{|c|c|c|c|c|c|c|c|c|}
\hline Spots : & 0 & $\mathrm{I}$ & 2 & 3 & 4 & 5 & Total & Difference \\
\hline $\mathrm{I} 95 \mathrm{I}$ & $4 \mathrm{I}$ & 7 & 37 & 8 & 5 & 0 & 98 & $\begin{array}{c}\text { N.S. }\left(\chi_{(3)}^{2}=6 \cdot 39\right. \\
\mathrm{P}=0 \cdot 05 \text { to } 0 \cdot \mathrm{I})\end{array}$ \\
$\mathrm{I} 953$ & $3^{2}$ & $\mathrm{I} 3$ & 52 & 6 & 2 & 0 & 105 & $\begin{array}{c}\text { N.S. }\left(\chi_{(3)}^{2}=2 \cdot 13\right. \\
\mathrm{P}=0 \cdot 5 \text { to } 0 \cdot 7)\end{array}$ \\
$\mathrm{I} 955$ & $\mathrm{I} 3$ & 9 & 33 & 6 & $\mathrm{I}$ & 0 & 62 & $\begin{array}{c}\text { P } \\
\text { I }\end{array}$ \\
\hline
\end{tabular}

The males, which emerge before the females, were somewhat scarce owing to the carliness of the season, but from a comparison of the small ig55 sample with that of I95 I (no male sample was taken in 1953) it is obvious that no significant change in spotting had occurred (see table 6).

The female sample was a larger one and is compared with those of $195 \mathrm{I}$ and 1953 in table 7 . 
A comparison of the samples in 1951 and 1953 , also of those in I953 and 1955, shows no significant deviation in spotting. Nor are the data for the three seasons, considered together, heterogeneous $\left(\chi_{(6)}^{2}=\mathrm{II} \cdot 5\right.$, for which $\mathbf{P}=0.05$ to $\left.0 \cdot \mathrm{I}\right)$. If, however, the I95I and I955 samples are compared, the value for $\chi_{(3)}^{2}=9 \cdot 16$, for which $P$ is between 0.05 and 0.02 . There is thus good evidence of a change in

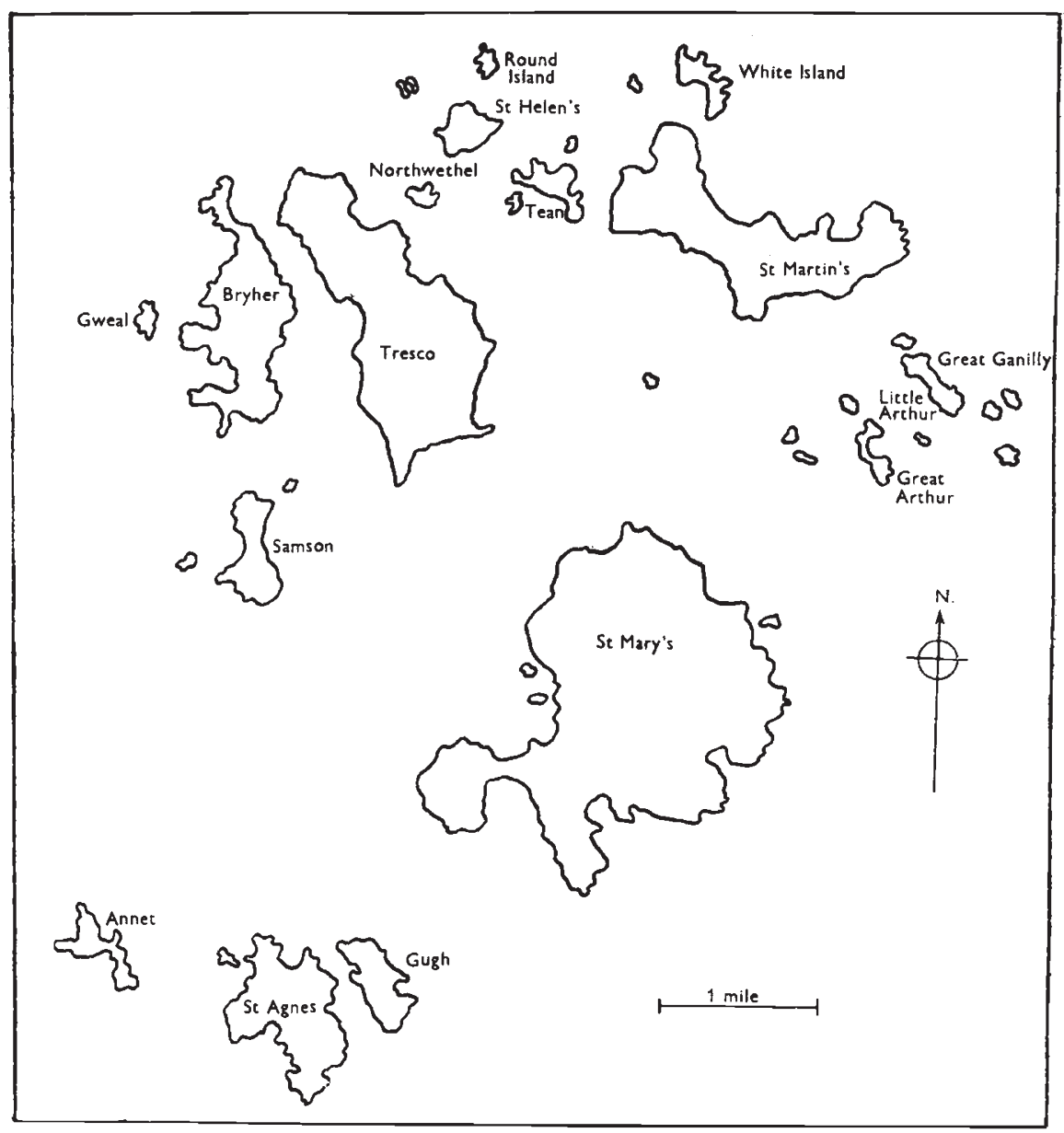

Reproduced by permission of The Society for Experimental Biology. Map. 2.

spot-distribution of female $M$. jurtina over a period of four years. This appears to be a consistent trend in the direction of reducing the mode at $\mathrm{o}$ spots and increasing that at 2 ; for though the 1953 sample does not differ significantly from the other two, it is intermediate between them in this respect. This is the first instance of its kind which we have encountered on a small island with a single, continuous population. The reasons for the change are, as yet, unknown, but they are no doubt ecological. The vegetation on Great Ganilly differs some- 
what from that of any other small island we have studied so far, consisting of a luxuriant growth of various grasses. There is, in addition, much heather interspersed with short grass, which is to be found mainly on the higher ground. It may be that in these rather abnormal circumstances the insect is particularly sensitive to small environmental changes, but only further study can provide the data necessary for a more critical analysis of this situation.

\section{(c) White Island (females only)}

This is connected with St Martin's at low water by a tumble of seaweed covered rocks 225 yards long, exposed at about half tide. Probably, therefore, the population of $M$. jurtina inhabiting it is quite isolated, for we have found elsewhere that roo to I50 yards of uninhabitable country is almost a complete barrier to this butterfly. Moreover, the distance involved is even greater than here indicated, for the insect is rare or absent at the end of White Island nearest to St Martin's, where the terrain, consisting of very short grass, rocks and some bracken, is unsuited to it.

White Island has an area of about 40 acres, so that it falls within the small-island group of Scilly. We collected on it in r953, r954 and 1955 , and obtained the results shown in table 12 . They are very consistent with one another: $\chi_{(4)}^{2}=2 \cdot 6$, for which $\mathrm{P}=0.7$ to 0.5 . The population resembles rather closely the one which is isolated at the southern end of Bryher (4), in having a single mode at o spots; also that occupying the mainland of southern England excluding Cornwall, though there the mode is much more pronounced $(2,3)$. It differs markedly from that found in the main (central) area of St Martin's (see tables 9 and I I).

When we proceed to a formal comparison between the two populations, we find that the difference at o spots contributes a $\chi^{2}$ of no less than i9. At one spot, the proportions in each population are nearly the same and the contribution is only 0.3 , while at 2 spots it is 9 and at 3 and more it is 19 owing to the almost complete absence of that condition on White Island. Thus the distinction between them proves to be very great. The problem raised by the similar spot-distributions of the $M$. jurtina population inhabiting White Island and that found on a small coastal strip of St Martin's immediately opposite is discussed on pp. 63 and 64 .

\section{THE LARGE ISLANDS}

\section{(a) Tresco (females only)}

We had already sampled the $M$. jurtina population on Tresco in r 950 and I95 I, and we did so again both in r954 and r955. The island may be said to fall into four main ecological divisions : the barren areas of rocky coast and poor heather country to the north, the great sub-tropical gardens with their sheltering pine woods, now 
maintained so successfully by the Dorrien-Smith family for over a century, the uncultivated coast region of marram grass and short dune-turf upon sand, and the agricultural lands. M. jurtina is to be found only in the last two of these, and on the agricultural land only on rough grass and along hedgerows. It occurs also in a few small isolated areas. The population inhabiting one of these is described and discussed on pp. 61 and 62.

Both in 1954 and I955 we collected over the extensive region where we had taken our previous samples. This we describe as the "Main Area". The insect was not particularly common in either year and we had some difficulty in catching sufficient numbers. Our results, and those obtained formerly, are given in table 9. An inspection of this table will indicate the close similarity of spot-distribution in this Main Area for all four years. This can be assessed from a table of General Contingency, in which the samples having three or more spots are accumulated to avoid unduly small or missing values. The association is measured by $\chi_{(9)}^{2}=4.8$, for which $\mathrm{P}=0.9$ to 0.8 . It will be appreciated, therefore, that the results are very concordant, and give no indication that the spot-distribution has changed during the period I950 to 1955 inclusive.

\section{(b) St Mary's (females only)}

A very considerable part of this, the largest of the Isles, provides a suitable habitat for $M$. jurtina, which is widely distributed over it, being found along hedges, on rough ground and in pastures. As we had only collected on St Mary's once previously, in I95I, it was a matter of much interest to do so again in 1954 and 1955 , and to determine whether the spot-distribution had remained constant over the whole period for which we now have data, as well as during the two intervening years for which no information is available. Our results for the three seasons in question are given in table 9. The agreement between them is measured by $\chi_{(6)}^{2}=5.9$, for which $\mathrm{P}=0.5$ to $0 \cdot 3 *^{*}$ Consequently they must be judged substantially similar.

\section{(c) St Martin's}

(i) Females. M. jurtina occurs commonly over a large area of St Martin's. It is to be found in regions of turf with marram grass along the coast, on rough ground, in pastures and by hedge sides. However, it is, as elsewhere, absent from heather moors and extensive areas of bracken. Such places, therefore, isolate a few small colonies here and there along the shore (see pp. $6_{3}-6_{4}$ ) from the main population of the island. The latter has already been studied in I950, I95 I and I953, and we obtained further samples of it in 1954 and 1955 . These data are given in table 9. The spot-distributions are in substantial

* Individuals with three or more spots were combined to avoid vory small numbers. 
agreement in all five years, their homogeneity over the whole period being measured by $\chi_{(12)}^{2}={ }_{1} \cdot 6$, for which $\mathrm{P}$ is just below 0.5 .

(ii) Males. We have tested the distribution of spotting in the males of $M$. jurtina extensively in the past. It has proved to be very similar not only on all the islands of Scilly, large and small, but throughout southern England, including Cornwall $(2,3)$. In view of shortage of time duc to other and more pressing aspects of the work, we obtained only one male sample on the large islands during the two years now under review. This was collected on St Martin's in 1955. It is strictly in accord with the established form of male spotting, having a single large mode at 2 spots. In table 8 this 1955 sample is compared with those taken there in three previous years. The over-all agreement is measured by $\chi_{(9)}^{2}=9 \cdot 6$, for which $\mathrm{P}=0.5$ to 0.3 .

TABLE 8

Spot-distributions of male Maniola jurtina from the Main Area of St Martin's

\begin{tabular}{|c|c|c|c|c|c|c|c|}
\hline Spots : & 0 & I & 2 & 3 & 4 & 5 & Tota! \\
\hline $\begin{array}{l}1950 \\
1951 \\
1953 \\
1955\end{array}$ & $\begin{array}{r}5 \\
8 \\
\cdots \\
\text { I }\end{array}$ & $\begin{array}{r}16 \\
18 \\
7 \\
9\end{array}$ & $\begin{array}{r}66 \\
\text { r } 99 \\
37 \\
49\end{array}$ & $\begin{array}{r}20 \\
43 \\
9 \\
15\end{array}$ & $\begin{array}{r}7 \\
18 \\
3 \\
7\end{array}$ & $\begin{array}{c}3 \\
7 \\
\ldots \\
\cdots\end{array}$ & $\begin{array}{r}117 \\
293 \\
56 \\
8 \mathbf{I}\end{array}$ \\
\hline & 14 & 50 & $35^{I}$ & 87 & 35 & 10 & 547 \\
\hline
\end{tabular}

(d) General comparison of female spotting on the large islands

We have already pointed out in a previous report (4) that those islands in the Scilly archipelago on which we have studied Maniola jurtina fall into three size-groups: (a) large islands of 682 acres or more, $(b)$ small islands of 40 acres or less, and $(c)$ two, Bryher and Samson, of intermediate size. Thus the large and small islands are of very distinct areas : the difference being seventeen times or more. The spot-distributions of the $M$. jurtina populations differ greatly from one to another of the small islands on each of which, however, they have remained constant as long as we have investigated them (4, and pp. $5^{1-57}$ of this paper). To this statement there are two exceptions : the marked and rapid change in one of the Tean populations associated with a complete alteration in the ecology of the area (p. 53), and the slow trend in spot-adjustment detected on Great Ganilly (p. 55). We have also shown (4) that neither Bryher nor Samson is inhabited by an extensive population, as are the large islands, but that there are two, or possibly more, restricted and isolated colonies on each. These, therefore, have the characteristics of those found on small islands. 
As already explained, the spot-distributions on each of the three large islands have remained constant throughout our period of study. Moreover, they are of similar form on all of them, being approximately flat topped with high frequencies at $o, I$ and 2 spots which do not differ significantly from one another.

It was essential to determine if the constancy and similarity of spotting on the three large islands, revealed by our previous studies (3), is confirmed by the data obtained in 1954 and 1955 . For the existence in $M$. jurtina of distinct types of population on the small and the large islands respectively is of much importance from an evolutionary point of view (3).

Our total results on all the large islands we have studied are shown

TABLE 9

Spot-distributions of female Maniola jurtina on three large islands in Scilly

\begin{tabular}{|c|c|c|c|c|c|c|c|c|c|c|c|c|c|}
\hline \multirow{2}{*}{ Spots } & \multicolumn{4}{|c|}{ Tresco } & \multicolumn{3}{|c|}{ St Mary's } & \multicolumn{5}{|c|}{ St Martin's } & \multirow{2}{*}{ Total } \\
\hline & $195^{\circ}$ & $195^{I}$ & I 954 & I 955 & $195^{\mathrm{r}}$ & 195 & 195 & 195 & I95 & I953 & 1954 & I955 & \\
\hline \multirow{7}{*}{$\begin{array}{l}\mathrm{O} \\
\mathrm{I} \\
2 \\
3 \\
4 \\
5\end{array}$} & 43 & 39 & 26 & 32 & 36 & 26 & 47 & 33 & 38 & 46 & 76 & 79 & $52 I$ \\
\hline & 37 & 40 & 28 & $3^{1}$ & 27 & 26 & 37 & 35 & 38 & 34 & 72 & 72 & 477 \\
\hline & $4^{I}$ & 47 & 36 & 27 & $3^{\mathrm{I}}$ & $3^{I}$ & 46 & 32 & 33 & 36 & 78 & 68 & 506 \\
\hline & 7 & 7 & 5 & 7 & 4 & I3 & is & 7 & 5 & 3 & 8 & 18 & 97 \\
\hline & 2 & I & I & 4 & 3 & 4 & 7 & 2 & 2 & I & 3 & 7 & 37 \\
\hline & $\ldots$ & I & $\ldots$ & $\ldots$ & $\ldots$ & ... & i & ... & $\ldots$ & $\ldots$ & $\ldots$ & $\ldots$ & 2 \\
\hline & 130 & 135 & 96 & IOI & IOI & 100 & ${ }^{15}$ & 109 & II 6 & 120 & 237 & 244 & 1640 \\
\hline
\end{tabular}

in table 9. Their homogeneity is measured by $\chi_{(33)}^{2}=36 \cdot 9 \cdot{ }^{*}$ For this, the expression $\sqrt{2 \chi^{2}}-\sqrt{2 n-1}$ supplies a normal deviate. Here $\sqrt{73 \cdot 8}-\sqrt{65}=0.53$. Thus the data for all the available years on all three large islands are effectively similar.

\section{ISOLATED AREAS ON THE LARGE ISLANDS}

We have suggested (4) that the remarkably characteristic and constant spot-distribution in the females on the three large islands has been developed in response to the average of the conditions existing in a considerable and diversified habitat. If this is so, we should expect that the isolation, or even partial isolation, of a colony on a small sector of one of the large islands might allow such a local population to achieve an equilibrium different from that which we have shown to be characteristic.

Several such restricted areas in which $M$. jurtina abounds have so far been found and in two of them, one on Tresco and one on St Martin's, spot-distribution data are available for two or more years.

* Individuals with three or more spots are combined to avoid very small or missing values. 


\section{(a) The "Farm Area" on Tresco}

In I954, we found a small and exceptional population occupying an entirely abnormal habitat immediately south of the farm buildings and estate works at New Grimsby, Tresco. Here, a number of huts had been erected during the I9I4-I 8 War. Their concrete foundations remain, and around them has grown up dense vegetation, highly peculiar for the island, of wild plants and garden escapes, which include: Mesembryanthemum, Hyoscyamus, mullein (Verbascum), thistles,

TABLE IO

Spot-distribution in female Maniola jurtina on the Main and "Farm" Areas of Tresco in 1954 and 1955

\begin{tabular}{|c|c|c|c|c|c|c|c|c|}
\hline Spots : & 0 & I & 2 & 3 & 4 & 5 & Total & Difference \\
\hline Main Area I 954 & 26 & 28 & 36 & 5 & I & 0 & 96 ) & $\chi_{(3)}^{2}=7 \cdot 7$ \\
\hline Farm Area I 954 & 5 & 6 & I 8 & 6 & 0 & 0 & $35\}$ & $\mathrm{P}=0.05$ to $0 . \mathrm{I}$ \\
\hline Main Area 1955 & 32 & $3 \mathrm{I}$ & 27 & 7 & 4 & 0 & $101)$ & $x_{(3)}^{2}=8 \cdot 10$ \\
\hline Farm Area I 955 & 23 & I6 & 40 & 6 & 4 & o & 89 & $P=0.02$ to 0.05 \\
\hline Main Area 1954 & 26 & 28 & 36 & 5 & I & 0 & $96)$ & $x_{(3)}^{2}=3.40$ \\
\hline Main Area I 955 & 32 & $3 I$ & 27 & 7 & 4 & 0 & IOI $j$ & $\mathrm{P}=0.3$ to 0.5 \\
\hline Farm Area I954 & 5 & 6 & I 8 & 6 & 0 & 0 & $35 !$ & $x_{(3)}^{2}=2 \cdot 40$ \\
\hline Farm Area I 955 & 23 & 16 & 40 & 6 & 4 & o & $89 i$ & $\mathrm{P}=0.3$ to 0.5 \\
\hline Main Area Total & $5^{8}$ & 59 & 53 & 12 & 5 & $o$ & $197\}$ & $\chi_{(3)}^{2}=1 \mathrm{I} \cdot 60$ \\
\hline Farm Area Total & 28 & 22 & $5^{8}$ & 12 & 4 & 0 & $124\}$ & $\mathrm{P}<0.0 \mathrm{I}$ \\
\hline
\end{tabular}

long grass, yarrow (Achillea), burdock (Arctium), yellow-horned poppy (Glaucium), bramble, bracken, foxgloves and nettles.

This area occupies only $200 \times 70$ yards. It is bounded by the farm buildings to the north and the shore to the west. To the south there is agricultural land unsuited to $M$. jurtina; in 1955 , this was becoming somewhat overgrown. On the eastern side is a road, beyond which is a ditch and hedge bordering the narrow piece of pasture at the edge of the Tresco Lake. This "Farm Area" is connected to our main collecting area by a path bordered by thick bracken and bramble, running to the south along the coast. It is probable that occasional insects migrate along this path, but no considerable flow has been observed, even on days when the species has been abundant.

The abnormal spot-distribution in the Farm Area, which is shown in table ro was discovered when we first collected from it in I954. In that year only 35 females were caught. The disparity between this exceptional population and that inhabiting the Main Area of Tresco in 1954 is measured by $\chi_{(3)}^{2}=7 \cdot 7$, for which $\mathrm{P}$ is just greater 
than $0 \cdot 05$. It was obviously of much interest to return to this area in 1955 and it will be seen that the population remained abnormal in this year. The probability of this disparity being due to chance sank below 0.05 with $\chi_{(3)}^{2}=8$. Io for the 1955 catch. Since the respective spot-distributions of both the Main Area and the Farm Area are homogeneous over the years 1954-55 (table 10), we considered it legitimate to add the data for both years, and this reduced the probability of the disparity in the Farm Area being due to chance to under o.0 I $\left(\chi_{(3)}^{2}=\mathrm{II} \cdot 6 \mathrm{o}\right)$.

Certain changes in the micro-ecology of the Farm Area were noted in 1955, for early in that year a piggery had been installed in the centre of it and the peculiar vegetation had been somewhat reduced and trampled upon. There is at present no indication whether these developments are significant in relation to the spot-distribution of $M$. jurtina or not.

We obtained mark-release-recapture data on the Farm Area population over a period of four days. Analysis of these data by the method of Dowdeswell, Fisher and Ford (I) proved difficult owing to the impossibility of finding a suitable survival ratio. If we had been able to devote a longer period to the study of this population, this difficulty could no doubt have been overcome. Our analyses, unsatisfactory though they proved to be, did nevertheless generally agree with our impression that the daily flying population in the Farm Area was of the order of Ioo-I 50 insects.

The results obtained in the Farm Area merit brief consideration in two respects. First, a practical point arises : they stress the extreme necessity in such work of relating the collecting to the ecology of the habitat. Had this sample been combined with the rest of the Tresco insects, an entirely false impression would have been produced; for the peculiarities of the insects inhabiting this exceptional situation would have been missed, while the total sample would have appeared to diverge from that taken in previous years with which, when restricted to comparable ecological conditions, it is in fact strictly concordant. Secondly, it is necessary to enquire why this population differs from that found throughout the rest of the island. There is a possibility that its numbers are small enough to be affected by genetic "drift", but the maintenance of the abnormality over two years at least, despite the probability of some leakage from the Main Area, points rather to the existence of some powerful selection pressure peculiar to the Farm Area. If the significant factors causing this pressure are constant, we should expect the population to respond by showing a constant, though divergent, spot-distribution; if they are being slightly varied, the response may be a gradual swing in the spotdistribution. Such a swing would be dependant on selectional forces, perhaps eventually analysable, rather than on chance alterations in gene-frequencies. We consider it most unlikely to be a coincidence that there is a correspondence between an area which is ecologically 
quite exceptional and a population of $M$. jurtina which shows such an unusual structure.

\section{(b) The coastal area on St Martin's opposite White Island}

We have shown on pp. $5^{8}$ and 59 that there is a large population of $M$. jurtina in the central area of St Martin's whose females have maintained a stable spot-distribution of the "flat-topped" kind, for at least five years. Round the coast of the island, however, there are a few small colonies which are isolated from the central populations by heath moor and extensive areas of bracken. Samples from these isolated populations have been taken and they have been found to diverge in various ways from the standardised female spot-distribution of the central one.

\section{TABLE II}

Spot-distribution in female Maniola jurtina on the Main Area of St Martin's and on the Coastal Area of St Martin's opposite White Island in the years 1953-55

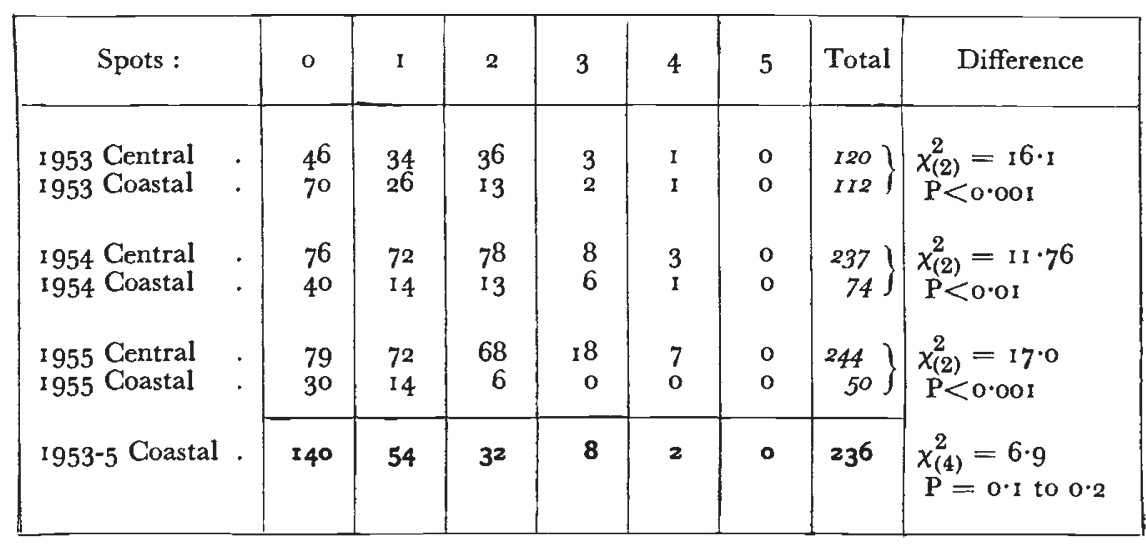

Confining our attention to one of these small populations for which we have data for the years $1953-55$, we find that within a strip of the St Martin's coast 300 yards long and from ro-80 yards in width, directly opposite White Island, the females of $M$. jurtina have consistently shown a spot-distribution with one large morle at o. This has not varied appreciably from year to year, and has always been extremely distinct from the population in the centre of St Martin's. Table I i illustrates this point.

We were at first considerably puzzled by this marked divergence. However, an ecological survey of the surrounding neighbourhood has shown us that isolation of the small coastal strip is indeed effective. Between it and the central region is interposed a waste of bracken, denuded rock and very short heather on podsolized soil. This barrier is about 250 yards wide and stretches to the coast on either side of the restricted area inhabited by $M$. jurtina. Accordingly it seems to us likely that this small coastal population has been able to adjust itself to the special micro-ecological conditions of its limited habitat. 
We must also here note, and table 12 demonstrates the fact, that the spot-distribution of the coastal population on St Martin's, opposite White Island, has in no year differed significantly from that of White Island itself. It has already been pointed out (p. 57) that $M$. jurtina must be effectively isolated on White Island. We have no difficulty in rejecting the hypothesis that isolated populations showing similar spot-distributions can arise only through migration. For instance,

TABLE 12

Spot-distribution in female Maniola jurtina on White Island and on the Coastal Area of St Martin's opposite White Island in the years 1953-55



Tean area 5 and Great Ganilly showed similar spot-distributions in 1951. Yet there are two miles of sea between them and the intervening islands of St Martin's and Arthur show completely dissimilar distributions. Clearly, migration is excluded as the cause of the similarity observed in this case.

It appears that there remain two plausible hypotheses by which we may hope to explain the observed similarity of the White Island population and that confined to the coastal strip of St Martin's opposite White Island. It may be due to an adjustment of both populations to an average of micro-ecological factors which happens to be similar in both habitats. Alternatively, while the operative ecological factors may differ in the two habitats, it may be that the two populations have adjusted themselves to them in ways which chance to have evoked similar spot-distributions. The development of experimental techniques capable of distinguishing between these possibilities is clearly desirable, and it is a project which we hope to undertake. 


\section{SUMMARY}

I. The results of two seasons' work, I954 and 1955, are summarised in this paper. A distinction is made between Small and Large Islands.

\section{Small islands}

2. The removal of cattle from Tean has so altered the ecology of the island that areas which formerly acted as barriers to $M$. jurtina have become colonised by it, and the reverse.

3. The population on Tean area I (see map I) has spread over area 2, yet it has retained its spotting characteristics which have persisted since 1946. Area 3 is now a barrier to the insect. The colony in area 5 has extended over area 4 , and its female spotdistribution has completely changed. The reason for this is discussed.

4. Female spotting on Great Ganilly is bimodal. It has shown a slow but significant trend from a greater mode at o spots and a smaller mode at 2 in 195 I to the reverse in 1955. No detectable difference in male spotting has taken place over this period.

5. White Island falls within the "small" island group of Scilly. The $M$. jurtina inhabiting it have a female spot-distribution entirely distinct from that of any other small island. This has remained constant since 1953 when it was first examined.

\section{Large islands}

6. Further female samples were taken on each of the three " large" islands (St Martin's, St Mary's, Tresco) in 1954 and 1955. The frequency distribution of spotting is the same on these three islands, and has remained so for all the years in which it has been studied.

7. Male spotting has not altered for any island or any year, including St Martin's 1955.

8. Here and there on the large islands small colonies are isolated by barriers from the main population. Two of these have been studied.

9. One of them occupies a small strip of ground on St Martin's opposite White Island. Here female spotting is quite different from that of the main population of St Martin's but identical with that on White Island. It is shown that the latter similarity is not likely to be due to migration.

10. Another such small isolated colony has been found on Tresco. It occupies an ecologically exceptional area, and the female spotdistribution is significantly different from that of the main population of the island. The origin and significance of this difference is discussed.

Acknowledgments.-We should like to express our grateful thanks to the Nuffield Foundation for their financial support of this work. We are indebted to the late Major A. A. Dorrien-Smith for his kind permission to camp on Tean.

\section{REFERENCES}

I. DOWDeswell, W. H., FISHER, R. A., AND FORD, E. B. 1949. Heredity, 3, 67-84.

2. DOWDESWELl, W. H., AND FORD, E. B. 1952. Heredity, 6, 99-IO9.

3. DOWDeswell, W. H., AND FORD, E. B. 1.953. Symposia Soc. Exp. Biol., 7, 254-273.

4. DOWDeswel.L, W. H., AND FORD, E. B. 1955. Heredity, 9, 265-272. 